\title{
Further studies on South African plants: Acaricidal activity of organic plant extracts against Rhipicephalus (Boophilus) microplus (Acari: Ixodidae)
}

\author{
Kevin W. Wellington, ${ }^{1}{ }^{*}$ Tlabo Leboho, ${ }^{1}$ Bellonah M. Sakong, ${ }^{2}$ Olubukola T. Adenubi, ${ }^{2}$ \\ Jacobus N. Eloff ${ }^{2}$ and Gerda Fouche, ${ }^{1} *$
}

${ }^{1}$ CSIR Biosciences, PO Box 395, Pretoria, South Africa

${ }^{2}$ Phytomedicine Programme, Department of Paraclinical Sciences, Faculty of Veterinary Sciences, University of Pretoria, Onderstepoort 0110, South Africa

*G.fouche@csir.co.za; Tel.: 012841 3815, FAX: 0128414790

*kwellington@csir.co.za; kwwellington@gmail.com; Tel.: 012841 3158,FAX: 0128414790

\section{Highlights}

- Several acetone and ethanol plant extracts exhibit acaricidal activity at a $1 \%$ concentration.

- The acetone stem extract from Cissus quadrangularis had a similar efficacy to that of chlorfenvinphos $(\mathrm{CM}=100)$ at a $0.03 \%$ concentration.

- The ethanol leaf and flower extract from Calpurnia aurea also had a similar efficacy to that of chlorfenvinphos $(\mathrm{CM}=100)$ at a $0.03 \%$ concentration.

\section{Graphical Abstract}

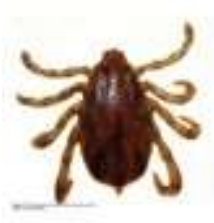

R.(B.) microplus

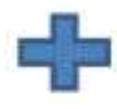

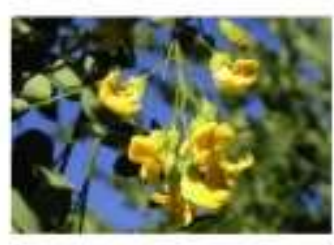

Calpurnia aurea
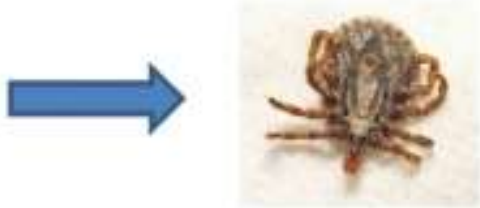

A dead tick 


\section{Abstract}

The goal of our research is to develop a lower cost eco-friendly tick control method because acaricides that are commonly used to control ticks are often toxic, harmful to the environment or too expensive for resource-limited farmers. Acetone and ethanol extracts were prepared and their acaricidal activities determined against the southern cattle tick, Rhipicephalus (Boophilus) microplus. A 1\% solution of each of the plant extracts was prepared for efficacy testing using the adapted Shaw Larval Immersion Test (SLIT). The acetone stem extract from Cissus quadrangularis (Vitaceae) and the ethanol leaf and flower extract from Calpurnia aurea (Fabaceae) had potent activity like that of the commercial acaricide, chlorfenvinphos [corrected mortality $(\mathrm{CM})=100.0 \%$ ]. The ethanol extracts of the stem of $C$. quadrangularis $(\mathrm{CM}=98.9 \%)$ and that of the roots, leaves and fruit of Senna italica subsp arachoides $(\mathrm{CM}=$ 96.7\%) also had good acaricidal activity. The toxicity of the plants was determined by screening against Vero cells and they were found to have low cytotoxicity. There is potential for the development of botanicals as natural acaricides against $R$. (B.) microplus that can be used commercially to protect animals against tick infestation. Further studies to isolate the acaricidal active compounds and to determine the environmental fate, species toxicity and skin toxicity of these plants species are, however, required before they can be considered as a treatment against ticks.

Key words: Rhipicephalus (Boophilus) microplus, SLIT bioassay, Toxicity bioassay, Acetone, Ethanol, Plant extracts, Acaricidal activity. 


\section{Introduction}

The southern cattle tick, Rhipicephalus microplus (Acari: Ixodidae), formerly known as Boophilus microplus (Murrell and Barker 2003), has established populations throughout the world in tropical and subtropical regions. It is responsible for significant financial losses associated with direct injury and with the transmission of haemoparasites to its host (Rachinsky et al. 2008).

Conventional tick control is accomplished by using chemical agents called acaricides which are applied as dips, sprays or may also be poured on at various frequencies. The disadvantages of acaricides are that they are expensive, ticks have developed resistance to them and the stable residues of conventional acaricides may pollute milk and meat products as well as the environment. Furthermore, these acaricides are not readily available to resources-limited farmers (Okello-Onen and Rutagwenda 1997). These farmers have resorted to low cost alternatives such as using plants in ethno-veterinary practices to control ticks (Njoroge and Bussmann 2006).

The growing demand for organic meat production and environmentally friendly acaracides has led to an intensification of scientific research on plant-based products that have acaricidal properties. Plants have been recognised as being potential sources of acaricidal agents (Franscisco et al. 2003). Major advantages of the use of plant-based products for tick control are that they are biodegradable and therefore less toxic to the environment and to nontargeted species (Liang et al. 2003).

We have previously reported on the acaricidal activity of organic extracts of South African plants against Rhipicephallus decoloratus (Koch, 1844) Acari: Ixodidae) (Fouche et al. 2016). Herein we report on some of the preliminary results of rapidly screening a large number of plant extracts against $R$. (B.) microplus. 


\section{Materials and methods}

The plants and methods followed were those described by Fouche et al. (2016).

Table 1. The corrected mortality $(\mathrm{CM})$ of the eleven indigenous South African plant species screened against $R$. (B.) microplus.

\begin{tabular}{|c|c|c|c|c|}
\hline Entry & $\begin{array}{l}\text { Plant and plant part } \\
\text { used in extraction }\end{array}$ & Solvent & $\begin{array}{c}\text { Mortality } \\
(\%)\end{array}$ & $\begin{array}{l}\text { CM } \\
(\%)\end{array}$ \\
\hline \multirow[t]{2}{*}{1} & Aloe rupestris (Leaves) & Acetone & 17.0 & 2.4 \\
\hline & & Ethanol & 54.2 & 46.1 \\
\hline \multirow[t]{2}{*}{2} & Calpurnia aurea (leaves, flowers) & Acetone & N.D. & N.D. \\
\hline & & Ethanol & 100.0 & 100.0 \\
\hline \multirow[t]{2}{*}{3} & Senna italica subsp arachoides & Acetone & N.D. & N.D. \\
\hline & (roots, leaves, fruit) & Ethanol & 97.2 & 96.7 \\
\hline \multirow[t]{2}{*}{4} & Cissus quadrangularis (stems) & Acetone & 100.0 & 100.0 \\
\hline & & Ethanol & 99.0 & 98.9 \\
\hline \multirow[t]{2}{*}{5} & Cleome gynandra (leaves) & Acetone & 46.0 & 36.5 \\
\hline & & Ethanol & 84.3 & 81.5 \\
\hline \multirow[t]{2}{*}{6} & Ficus sycomorus (Bark \& stems) & Acetone & 42.1 & 31.9 \\
\hline & & Ethanol & 29.0 & 16.5 \\
\hline \multirow[t]{2}{*}{7} & Monsonia angustifolia (whole plant) & Acetone & 45.4 & 35.8 \\
\hline & & Ethanol & 61.4 & 54.6 \\
\hline \multirow[t]{2}{*}{8} & Pelargonium luridum (whole plant) & Acetone & 46.8 & 37.4 \\
\hline & & Ethanol & 66.9 & 61.1 \\
\hline \multirow[t]{2}{*}{9} & Schkuhria pinnata (whole plant) & Acetone & 19.7 & 5.5 \\
\hline & & Ethanol & 36.3 & 25.1 \\
\hline \multirow[t]{2}{*}{10} & Sclerocarya birrea (bark, root) & Acetone & 41.1 & 30.7 \\
\hline & & Ethanol & 32.7 & 20.8 \\
\hline \multirow[t]{2}{*}{11} & Tabernaemontana elegans (leaves) & Acetone & 34.6 & 23.1 \\
\hline & & Ethanol & 16.5 & 1.8 \\
\hline 12 & Diluent (negative control) & - & 15 & 15 \\
\hline 13 & Chlorfenvinphos & - & 100 & 100 \\
\hline
\end{tabular}

N.D. - not determined because larvae too mixed up with extract debris to be evaluated Negative control: consisted of only diluent (acetone used to prepare extractions) Positive Control: 300 ppm (Field concentration of Chlorfenvinphos) Supadip 30\% m/v $\mathrm{CM}=$ corrected mortality 


\section{Results}

\subsection{Determination of the acaricidal activity}

The results of testing the plant extracts for efficacy using the adapted SLIT are shown in Table 1. The most potent extracts had activity at $1 \%$ concentration that was similar to chlorfenvinphos at a $0.3 \%$ concentration. Among the acetone extracts $C$. quadrangularis (stem) had the best activity $(\mathrm{CM}=100 \%)$. The ethanol extract of $C$. aurea (leaves, flowers) also had potent activity like chlorfenvinphos $(\mathrm{CM}=100 \%)$. . quadrangularis $($ stem $)$ and $S$. italica subsp arachoides (roots, leaves, fruit) ethanol extracts had good activity $(\mathrm{CM}=98.9 \%$ and $96.7 \%$ respectively) while $P$. luridum (whole plant) and $M$. angustifolia (whole plant) had a much lower activity $(\mathrm{CM}=61.1 \%$ and $54.6 \%$ respectively). The toxicity of the plant extracts against Vero cells was determined in a previous study and was found to be acceptable (Fouche et al. 2016).

\section{Discussion}

The ethanol extract from $C$. aurea (leaves, flowers) had potent activity similar to chlorfenvinphos $(\mathrm{CM}=100.0 \%)$ at a $0.3 \%$ concentration. The main chemical constituents of C. aurea are phenolic compounds (Adedapo et al. 2008) It may therefore be concluded that the efficacy of the ethanol extract $C$. aurea (leaves) may be due to its ability to kill or severely compromise the mobility of ticks.

Phytochemical screening of the leaf extract prepared from $70 \%$ ethanol was done and several chemical constituents were found to be present such as alkaloids, cardiac glycosides flavonoids, phenols, saponins, steroids, tannins, and terpenoids (Mulata et al. 2015). Tanninrich plant extracts have been reported to have acaricidal effects against larvae of $R$. (B.) microplus (Fernández-Salas et al. 2011). Phenols, terpenoids, and alkaloids are also known to 
possess insecticidal ctivities (Ghosh et al. 2007). Alkaloids have neurotoxic properties which cause mortality (Wink 2012).

The fact that $C$. aurea (leaves, flowers) have potent acaricidal activity is important for a field application of tick control by rural pastoralists. There is thus potential for $C$. aurea (leaves, flowers) to be used for tick control since this plant species is found throughout Africa and also has the ability to resist drought and overgrazing. The potential value of $C$. aurea to both commercial stock farmers and seminomadic pastoralists is further enhanced by the fact that this plant species is easy to cultivate. Since this plant is not toxic to the environment it will be an ideal component of integrated pest management systems (Liang et al. 2003) and therefore the practical and economic aspects of the exploitation of $C$. aurea should therefore be investigated.

The ethanol extract (roots, leaves, fruit) of Senna italica subsp arachoides $(\mathrm{CM}=96.7 \%)$ also had good acaricidal activity. Elsayed et al. (1992) isolated flavonoids, tamarixetin (3rutinoside-7-rhamnoside), $\beta$-sitosterol, stigmasterol, $\alpha$-amyrin, $\quad 1,5$-dihydroxy-3-methyl anthraquinone and anthraquinone from the aerial parts of $S$. italica subsp arachoides. More recently, Asfour et al. (2015), isolated compounds from the methanol extract of the aerial parts such as $\beta$-sitosterol (1), (22E)-3- $\beta$-hydroxycycloart-22-en-24-one, uvaol, daucosterol, methyl-3,4-dihydroxybenzoate, emodin, 4-hydroxyphenyl- $O$ - $\beta$-D-glucopyranoside, aloin $\mathrm{B}$, and rutin. Since methanol and ethanol have similar polarity it is likely that these compounds were also extracted with ethanol and would thus be present in the ethanol extract. These compounds may thus have contributed to the acaricidal activity of Senna italica subsp arachoides (roots, leaves, fruit).

The acetone stem extract of $C$. quadrangularis (stem) had potent activity like chlorfenvinphos $(\mathrm{CM}=100.0 \%)$ at a $0.3 \%$ concentration while the stem ethanol extract had almost similar activity $(\mathrm{CM}=98.9 \%)$. Two steroidal principles and two asymmetric 
tetracyclic triterpenoids were found in the stem of $C$. quadrangularis. There have also been reports of $\beta$-sitosterol, $\delta$-amyrin, $\delta$-amyrone, and flavonoids (quercetin), having different potential metabolic and physiological effects, being present (Jainu and Devi, 2004; Jakikasem et al., 2000). Unique stilbene derivatives termed quadrangularins A, B and C (Adesanya et al., 1999) have also been reported. A phytochemical analysis of the stem ethanolic extract revealed the presence of alkaloids, flavonoids, phenols and tannins in C. quadrangularis (Chidambara Murthy et al., 2003). Thus, the acaricidal activity of the stem extract of $C$. quadrangularis could be attributed to one or several of the compounds present in it.

The ethanol extract of $C$. gynandra (leaves) had potent acaricidal activity $(\mathrm{CM}=81.5 \%)$ while the acetone extract had no activity. In a phytochemical analysis study of the leaf extract of C. gynandra prepared from $90 \%$ ethanol several chemical constituents such as cardiac glycosides, cyanogenetic glycosides, triterpenes, saponins, flavonoids, phenols and tannins were found to be present (Anbazhagi et al. 2009). In a more recent study by Srinivas et al. (2014) steroids and alkaloids were reported in addition to several of the compounds reported by Anbazhagi et al. (2009). The antimicrobial activity of $C$. gynandra has been due to bioactive constituents such as tannins, flavonoids, alkaloids and saponins. These bioactive constituents may thus also have been responsible for the acaricidal activity of $C$. gynandra (leaves) in this study.

For $M$. angustifolia (whole plant) only the ethanol extract exhibited activity $(\mathrm{CM}=54.6 \%)$. This was also the case for P. luridum (whole plant) (Ethanol: $\mathrm{CM}=61.1 \%$ ). Lignans are a group of naturally occurring phenolic compounds and Khorombi (2006) isolated five aryl naphthalene lignans (suchilactone, justicidin A, 5-methoxyjusticidin A, chinensinaphthol, retrochinensinaphthol methyl ether and) during the fractionation of the organic (methanoldichloromethane) extract of $M$. angustifolia. Podophyllotoxin, a naturally occurring aryltetralin lignan, has interesting insecticidal and antifungal activities (Wang et al. 2014). 
The lignans isolated from $M$. angustifolia (whole plant) may thus be responsible or may have contributed to the acaricidal activity in this present study.

In the previous study all the plant extracts had low toxicity in the cytotoxicity assay (Fouche et al. 2016). When comparing the activity of the acetone and ethanol plant extracts against $R$. (B.) microplus to that against $R$. (B.) decoloratus, it is evident that more extracts were active and had a higher activity against $R$. microplus. Thus, it appears that $R$. (B.) microplus is more susceptible to the effects of the active principles in the extracts than $R$. (B.) decoloratus.

Ethno-veterinary leads are valuable in selecting species to be screened for the discovery of novel, natural acaricides for combatting the southern cattle tick, $R$. (B.) microplus, and other tick species.

\section{Conclusion}

Two plant species, tested as a $1 \%$ concentration of the plant extract, have potent acaricidal activities against $R$. (B.) microplus when compared to chlorfenvinphos at $0.3 \%$. The eleven South African plants used in ethno-veterinary medicine in this study had relatively low toxicity against Vero cells. There is potential for these plants to be developed as acaricides to overcome complications linked to the use of chemical acaricides. From all the plants tested $C$.

quadrangularis, $C$. aurea and S. italica subsp arachoides could be good alternatives in an integrated control effort against the southern tick, $R$. (B.) microplus. Further studies to isolate the acaricidal active compounds and to determine the environmental fate, species toxicity and skin toxicity of these plants species before they can be considered as a treatment against ticks, are warranted. 


\section{Conflict of interest}

The authors declare that they have no competing interests.

\section{Acknowledgement}

The authors thank the Technology Innovation Agency (TIA) of South Africa for financial support.

\section{References}

Abdel-Shafy, S., Zayed, A.A., 2002. In vitro acaricidal effect of plant extract of neem seed oil (Azadirachta indica) on egg, immature and adult stages of Hyalomma anatolicaum excavatum (Ixodidoidea; Ixodidae). Vet. Parasitol. 106, 89-96.

Adesanya, S.A., Nia, R., Martin, M.T., Boukamcha, N., Montagnac, A., and Pais, M., 1999. Stilbene derivatives from Cissus quadrangularis. J. Nat. Prod. 62(12), 1694-1695.

Adedapo, A.A., Jimoh, F.O., Koduru, S., Afolayan, J.A., Masika, P., 2008. Antibacterial and antioxidant properties of the methanol extracts of leaves and stems of Calpurnia aurea. BMC Complement. Altern. Med. 8(53), 1-8.

Asfour, H.Z., Ibrahim, S.R.M., Mohamed, G.A., 2015. Antimicrobial activity of extracts and compounds isolated from Cassia italica aerial parts. Int. J. Phyto. Pharm. 6(2), 95-100.

Anbazhagi, T., Kaduval, K., Suguna, G., Petrus, A.J.A., 2009. Studies on the pharmacological and in vitro antioxidant potential of Cleome gynandra Linn. Leaves. Nat. prod. radiance $8(2), 151-157$. 
Bram, R.A., 1983. Tick-borne livestock diseases and their vectors. 1. The global problem. Wld Anim. Rev. (FAO) 36, 1-5.

Chidambara Murthy K.N., Vanitha, A., Mahadeva Swamy, M., Ravishankar, G.A. 2003. Antioxidant and antimicrobial activity of Cissus quadrangularis L. J. Med. Food. 6(2), 99105.

Elsayed, N.H., Abu-Dooh, A.M., Elkhrisy, E.A.M., Mabry, T.J. 1992. Flavonoids of Cassia italica. Phytochem. 31(6), 2187.

Fernandes, F.F., Freitas, E.P.S., 2007. Acaricidal activity of an oleoresinous extract from Copaifera reticulata (Leguminosae: Caesalpinioideae) against larvae of the southern cattle tick, Rhipicephalus (Boophilus) microplus (Acari: Ixodidae). Vet. Parasitol. 147, 150-154.

Fernández-Salas, A., Alonso-Díaza, M.A., Acosta-Rodrígueza, R., Torres-Acostab, J.F.J., Sandoval-Castrob, C.A., Rodríguez-Vivas, R.I., 2011. In vitro acaricidal effect of tannin-rich plants against the cattle tick Rhipicephalus (Boophilus) microplus (Acari: Ixodidae). Vet. Parasitol. 175, 113-118.

Fouche, G., Ramafuthula, M., Maselela, V., Mokoena, M., Senabe, J., Leboho, T., Sakong, B.M., Adenubi, O.T., Eloff, J.N., Wellingtona, K.W., 2016. Acaricidal activity of the organic extracts of thirteen South African plants against Rhipicephalus (Boophilus) decoloratus (Acari: Ixodidae). Vet. Parasitol. 224, 39-43.

Franscisco, M.C., Carlos, C.V., Manual, R., Jorge, M.T., Jorge, S.C., Miguel, R.P., 2003. Repellence of Boophilus microplus larvae in Astyposanthes humilis and S. hamata plants. Parasitol. atinoam. 58, 118-121. 
Ghosh, S., Azhahianambi, P., Yadav, M.P., 2007. Upcoming and future strategies of tick control: a review. J. Vector Borne Dis. 44(2), 79-89.

Jainu M., Devi C.S., 2004. Effect of Cissus quadrangularis on gastric mucosal defensive factors in experimentally induced gastric ulcer- a comparative study with Sucralfate. J. Med. Food 7(3), 372-376.

Jakikasem, S., Limsiriwong, P., Kajsongkarm, T., Sontorntanasart, T., 2000. Phytochemical study of Cissus quadrangularis. Thai J. Pharm. Sci. 24, 25.

Khorombi, T.E., 2006, A chemical and pharmacological investigation of three South African plants. M.Sc dissertation, University of KwaZulu Natal South Africa, Pietermaritzburg, School of Chemistry.

Liang, G.M., Chen, W., Liu, T.X., 2003. Effects of three neem based insecticides on diamondback moth (Lepidoptera: Plutellidae). Crop Protection. 22, 333-40.

Magano S. R., Thembo K. M., Ndlovu S. M., Makhubela N. F. H., 2008. The anti-tick properties of the root extracts of Senna italica subsp. Arachoides. Afr. J. Biotechnol. 7(4), 476-481.

Malonza, M.M., Dipeolu, O.O., Amoo, A.O., Hassan, S.M., 1992. Laboratory and field observations on anti-tick properties of the plant Gynandropsis gynandra (L.), Brig. Vet. Parasitol. 42, 123-136.

Mulata, H.N., Gnanasekaran, N., Melaku, U., Daniel, S., 2015. Phytochemical Screening and Assessment of In Vitro Antioxidant Activities of Calpurnia aurea Seeds and Leaves. Int. J. Pharm. Pharm. res. 2(2), 1-12. 
Murrell, A., Barker, S. C., 2003. Synonymy of Boophilus Curtice, 1891 with Rhipicephalus Koch, 1844 (Acari: Ixodidae). Syst. Parasitol. 56(3), 169-172.

Njoroge, G.N., Bussmann, R.W., 2006. Herbal usage and informant consensus in ethnoveterinary management of cattle diseases among the kikuyus (Central Kenya). J. Ethnopharmacol. 108, 332-339.

Okello-Onen, J., Rutagwenda, T., 1997. A Study on the status of East coast-fever, causes of calf mortality and abortion in Ankole cattle in ankole ranching scheme, Mbarara District, Uganda. Final Report, GTZ project, Sanga, Mbarara. p. 36.

Rachinsky, A., Guerrero, F.D., Scoles, G.A., 2008. Proteomic profiling of Rhipicephalus (Boophilus) microplus midgut responses to infection with Babesia bovis. Vet. Parasitol. 152, 294-313.

Srinivas, R., Jyothi Chaitanya, P., Chandrashekar, R., Lakshmi Bhavani, N., 2014. Analysis of Preliminary phytochemicals of leaf extracts of Cleome gynandra L. World J. Pharm. Sci. 2(9), 1043-1045.

Wang, Y., Yu, X., Zhi, X., Xiao, X., Yang, C., Xu, H., 2014. Synthesis and insecticidal activity of novel hydrazone compounds derived from a naturally occurring lignan podophyllotoxin against Mythimna separata (Walker). Bioorg. Med. Chem. Lett. 24, 26212624.

Wink, M., 2012. Medicinal plants: a source of anti-parasitic secondary metabolites. Molecules 17(11), 12771-12791. 